\title{
Platelet-derived growth factor (PDGF)-BB- mediated induction of monocyte chemoattractant protein 1 in human astrocytes: implications for HIV-associated neuroinflammation
}

\author{
Crystal Bethel-Brown ${ }^{1}$, Honghong Yao ${ }^{1}$, Guoku Hu ${ }^{2}$ and Shilpa Buch ${ }^{1,3^{*}}$
}

\begin{abstract}
Chemokine (C-C motif) ligand 2, also known as monocyte chemoattractant protein 1 (MCP-1) is an important factor for the pathogenesis of HIV-associated neurocognitive disorders (HAND). The mechanisms of MCP-1-mediated neuropathogenesis, in part, revolve around its neuroinflammatory role and the recruitment of monocytes into the central nervous system (CNS) via the disrupted blood-brain barrier (BBB). We have previously demonstrated that HIV-1/HIV-1 Tat upregulate platelet-derived growth factor (PDGF)-BB, a known cerebrovascular permeant; subsequently, the present study was aimed at exploring the regulation of MCP-1 by PDGF-BB in astrocytes with implications in HAND. Specifically, the data herein demonstrate that exposure of human astrocytes to HIV-1 LAI elevated PDGF-B and MCP-1 levels. Furthermore, treating astrocytes with the human recombinant PDGF-BB protein significantly increased the production and release of MCP-1 at both the RNA and protein levels. MCP-1 induction was regulated by activation of extracellular-signal-regulated kinase (ERK)1/2, c-Jun N-terminal kinase (JNK) and p38 mitogen-activated protein (MAP) kinases and phosphatidylinositol 3-kinase (PI3K)/Akt pathways and the downstream transcription factor, nuclear factor $\mathrm{KB}(\mathrm{NFKB})$. Chromatin immunoprecipitation (ChIP) assays demonstrated increased binding of NFKB to the human MCP-1 promoter following PDGF-BB exposure. Conditioned media from PDGF-BB-treated astrocytes increased monocyte transmigration through human brain microvascular endothelial cells (HBMECS), an effect that was blocked by STI-571, a tyrosine kinase inhibitor (PDGF receptor (PDGF-R) blocker). PDGF-BB-mediated release of MCP-1 was critical for increased permeability in an in vitro BBB model as evidenced by blocking antibody assays. Since MCP-1 is linked to disease severity, understanding its modulation by PDGF-BB could aid in understanding the proinflammatory responses in HAND. These results suggest that astrocyte activation by PDGF-BB exaggerates monocyte recruitment into the brain via MCP-1 and underscores the critical role astrocytes play in HAND.
\end{abstract}

\section{Background}

HIV-associated neurocognitive disorders (HAND) remain a common complication of HIV infection affecting up to $60 \%$ of infected individuals despite the use of antiretroviral therapy (ART) [1]. With the advancement of ART the prevalence of HAND has actually increased,

\footnotetext{
* Correspondence: sbuch@unmc.edu

'Department of Pharmacology and Experimental Neuroscience, University of Nebraska Medical Center, Omaha, NE 68198, USA

${ }^{3}$ Department of Pharmacology and Experimental Neuroscience, 985880 Nebraska Medical Center (DRC 8011), University of Nebraska Medical Center, Omaha, NE 68198-5880, USA

Full list of author information is available at the end of the article
}

partly due to both increased survival rates of HIVinfected individuals and to the reduced ability of most of these drugs to cross the blood-brain barrier (BBB). Among the factors involved in the pathogenesis of HAND, influx of HIV-infected monocytes in response to the chemokine monocyte chemoattractant protein 1 (MCP-1) via a breached endothelial barrier, plays a critical role in disease pathogenesis. MCP-1 plays a vital role in the recruitment of monocytes into the brain contributing to neuroinflammation and $\mathrm{BBB}$ disruption $[2,3]$. This chemokine has been extensively studied and is expressed by a number of cell types including astrocytes, 
microglia and neurons [4,5]. Elevated expression of MCP-1 has been demonstrated in various diseases including multiple sclerosis, amyloid lateral sclerosis, lupus nephritis, peripheral neuropathy and Alzheimer's disease [6-13]. While increased expression of MCP-1 has been shown to correlate with $\mathrm{HIV}$-associated central nervous system (CNS) complications, regulation of this chemokine in the context of HIV disease remains less clear. Understanding the molecular mechanisms modulating MCP-1 may thus provide insights into development of therapeutic targets for many neurodegenerative diseases including HAND.

Platelet-derived growth factor (PDGF) is a well known and potent inducer of MCP-1. The PDGF family of proteins is very closely related to the vascular endothelial growth factor (VEGF) family and is highly conserved throughout the animal kingdom [14]. These proteins are usually expressed as dimers: PDGF-A and PDGF-B can form homodimers or heterodimers, and PDGF-C and PDGF-D form homodimers. For the sake of clarity, in this study, PDGF-B refers to the RNA expression, whereas PDGF-BB refers to the protein expression of these genes. Many studies on PDGF have focused primarily on its mitogenic effects [15-17], however, divergent effects of PDGF are rapidly emerging. For example, recent studies by Lawrence et al. have demonstrated PDGF to be a cerebrovascular permeant that can disrupt $\mathrm{BBB}$ integrity during ischemic stroke conditions [18]. Along similar lines, it has been shown that PDGF-BB can disrupt $\mathrm{BBB}$ via the modulation of molecules important in maintaining tight junctions such as ZO-1 and adhesion molecules [19].

Since astrocytes are a major source of MCP-1 in the brain and PDGF-BB has been shown to be an inducer of MCP-1, the purpose of this study was to explore the modulation of MCP-1 by PDGF-BB released from HIVtreated astrocytes. We hypothesize that PDGF-BB induced by HIV-1/HIV-1 Tat can result in astrocytic activation and release of $\mathrm{MCP}-1$ and $\mathrm{BBB}$ disruption. The data demonstrate that the exposure of human astrocytes to HIV-1 LAI resulted in the induction of PDGF at both the mRNA and protein levels. To explicate the mechanism/s involved in PDGF-BB/MCP-1 interaction, human astrocytes were then treated with PDGF-BB and monitored for expression of MCP-1. Utilizing pharmacological and genetic approaches we demonstrate the involvement of extracellular-signal-regulated kinase (ERK)1/2, c-Jun N-terminal kinase (JNK) and p38 mitogen-activated protein kinases (MAPKs), Phosphatidylinositol 3-kinase (PI3K)/Akt pathways and the transcription factor nuclear factor $\kappa \mathrm{B}(\mathrm{NF} \kappa \mathrm{B})$ in PDGF-BBmediated induction of $\mathrm{MCP}-1$ in astrocytes. Because both PDGF-BB and MCP-1 are known to affect the BBB and since astrocytic end-feet processes are in close contact with the endothelia, we also addressed the functional implications this may have on the BBB. Using pharmacological and neutralizing antibody approaches, we reveal that both PDGF-BB and MCP-1 play critical roles in reducing the integrity of the $\mathrm{BBB}$. These data highlight the role of PDGF-BB in astrocytic release of MCP-1, which in turn, is critical for recruitment of monocytes across the BBB. Taken together, these studies underscore the role of PDGF signaling as a potential therapeutic target of HAND.

\section{Materials and methods \\ Materials}

Recombinant human PDGF-BB was purchased from R\&D Systems (Minneapolis, MN, USA). All experiments involving the treatment of cells with exogenous PDGF$\mathrm{BB}$ were conducted under serum-free conditions because serum induces PDGF. STI-571, an inhibitor of tyrosine kinase receptors, was obtained from Novartis (Basel, Switzerland). The specific phosphatidinylinositol-3' kinase (PI3K) inhibitor LY294002, mitogen-activated protein (MAP) kinase kinase (MEK) inhibitor U0126 and p38 mitogen activated kinase (p38) inhibitor SB203558 were purchased from Promega (Madison, WI, USA). The JNK inhibitor SP600125 was purchased from Assay Designs (Ann Arbor, MI, USA). MCP-1 neutralizing antibody was obtained from eBioscience (San Diego, CA, USA). The C-C chemokine receptor type 2 (CCR2) antagonist, RS 102895, was purchased from Sigma (St Louis, MO, USA). The chromatin immunoprecipitation (ChIP) assay kit was obtained from Upstate, (Billerica, MA, USA).

\section{Cell culture and cell lines}

The human astrocytic cell line A172 (no. CRL-1620; American Type Culture Collection (ATCC)) were cultured as described previously [20] and maintained in Dulbecco's modified Eagle's medium (DMEM) high glucose medium containing $10 \%$ heated-inactivated fetal bovine serum, $2 \mathrm{mM}$ glutamine, penicillin (100 units/ $\mathrm{ml})$, streptomycin $(100 \mu \mathrm{g} / \mathrm{ml})$, essential amino acids and vitamins. In this study, A172 cells were used within 30 passages. Human primary astrocytes were obtained from ScienCell Research Laboratories (Carlsbad, CA, USA) and were cultured in DMEM/F12 medium (Invitrogen Life Technologies, Carlsbad, CA, USA) containing 10\% heat-inactivated fetal bovine serum (FBS), 2 mM glutamine, sodium bicarbonate, gentamicin, non-essential amino acids and vitamins. Primary human brain microvascular endothelial cells (HBMECs) obtained from Dr Monique Stins (The Johns Hopkins University, Baltimore, MD) were cultured in RPMI 1640 medium containing $10 \%$ heat-inactivated fetal bovine serum, 10\% Nu-Serum, $2 \mathrm{mM}$ glutamine, $1 \mathrm{mM}$ pyruvate, 
penicillin $(100 \mathrm{U} / \mathrm{ml})$, streptomycin $(100 \mu \mathrm{g} / \mathrm{ml})$, essential amino acids, and vitamins according to our previous publication [21].

\section{Cell treatment}

Human astrocytes were serum starved overnight prior to treatment. The HIV-1 LAI used in this study was propagated in stimulated peripheral blood mononuclear cells (PBMCs) [22] (supplied by Dr Howard Gendelman, University of Nebraska Medical Center, Omaha, NE, USA). The rationale for using a $\mathrm{C}-\mathrm{X}-\mathrm{C}$ chemokine receptor type 4 (CXCR-4)-tropic virus is based upon previous studies demonstrating the susceptibility of astrocytes to CXCR4-tropic viruses [23,24]. In the pharmacological inhibitor studies, the cells were pretreated with inhibitors specific for MEK (U0126, $1 \mu \mathrm{M})$, JNK (SP600125, $10 \mu \mathrm{M})$, P38 (SB20358, $1 \mu \mathrm{M}$ ) and PI3K (LY294002, 1 $\mu \mathrm{M})$ for $1 \mathrm{~h}$ prior to PDGF-BB exposure. The inhibitors were not removed from the astrocytes during PDGF-BB treatment and concentrations utilized in this study were based upon our previous studies [25].

\section{MCP-1 protein analysis by enzyme-linked immunosorbent} assay (ELISA)

MCP-1 levels were examined using an MCP-1 ELISA kit purchased from R\&D Systems. Samples were analyzed for MCP-1 protein according to the manufacturer's instructions in triplicates determined in at least three independent experiments.

\section{Reverse transcription and real-time RTPCR (RT-PCR)}

Total RNA was extracted using Trizol reagent according to the manufacturer's protocol (Invitrogen). RNA ( $1 \mu \mathrm{g})$ was used for cDNA production according to manufacturer's instructions (Thermo Scientific, Waltham, MA, USA). The sequences of primers used for human MCP-1 (GenBank accession number NM 002982) were as follows: sense: CAGCAGGTGTCCCAAAGAAGCTGT antisense: CCATTCCTTATTGGGGTCAGCACAGA. The sequences of primers used for glyceraldehyde-3phosphate dehydrogenase (GAPDH) (GenBank accession number NM 002046) were as follows: sense: TGCACC ACCAACTGCTTAGC; antisense: GGCATGGACTGTG GTCATGAG. The primers for CCR2 (GenBank accession number NM 001123396) were as follows: first round sense: TCTGGAGACCTCAACCAAATG; antisense: GGAAATGCGTCCTTGTTCAA. The primers used in the second round were as follows: sense: CCCTGTAT CTCCGCCTTCACT; antisense: TTCAGCTTGTGGC TTGTCTCA. Quantitative analyses of mRNA were conducted using an ABI 7500 Fast Real-Time PCR system (Applied Biosystems, Foster City, CA, USA). The primers for PDGF-B, MCP-1 and 18S were purchased from SA Biosciences (Frederick, MD, USA). Data were normalized using $\mathrm{Ct}$ values for GAPDH or $18 \mathrm{~S}$ in each sample. To calculate relative amounts mRNA, the average $\mathrm{Ct}$ values were subtracted from GAPDH or $18 \mathrm{~S}$ values for each target gene to provide changes in $\mathrm{Ct}$ value. Fold change in expression was calculated as $\log _{2}$ relative units.

\section{Flow cytometry}

Untreated human primary astrocytes and A172 human astrocytes were collected in cold phosphate-buffered saline (PBS) and ethylenediaminetetra-acetic acid (EDTA) (5 mM) followed by incubation with anti-PDGF receptor $\alpha$ (PDGF-R $\alpha)(C D 140 \alpha ; 1: 5)$ and anti-PDGF-R $\beta$ (CD140 $\beta$; 1:5) BD LSR II (BD Biosciences, San Jose, CA, USA) was used for fluorescence acquisition, and data were analyzed with FACS Diva software (BD Biosciences).

\section{Western blotting}

PDGF-BB treated astrocytes were lysed using the Mammalian Cell Lysis kit (Sigma) and the NE-PER Nuclear and Cytoplasmic Extraction kit (Pierce, Rockford, IL, USA) as per manufacturer's instructions. Cell lysates were subjected to separation by $12 \%$ sodium dodecyl sulfate polyacrylamide gel electrophoresis (SDS-PAGE) (30 $\mu \mathrm{g}$ protein per well) and transferred to polyvinylidene difluoride (PVDF) membranes. The blots were blocked with 5\% non-fat dry milk in PBS. Western blots were then probed with antibodies recognizing phosphorylated forms of ERK1/2, JNK, p38 and Akt and total forms of ERK1/2, JNK, and Akt (Cell Signaling, Danvers, MA, USA; 1:500); NFkB-p65 and phosphorylated inhibitor of $\kappa B(p І \kappa B)$ Cell Signaling, $(1: 1,000)$; Histone $(1: 1,000)$ and $\beta$-actin antibodies (Santa Cruz Biotechnologies, Santa Cruz, CA, USA; 1:5,000). Signals were detected by chemiluminescence (Pierce).

\section{Transduction with adenoviral constructs}

A172 cells were infected with adenoviral constructs containing either wild-type (WT) or dominant-negative (DN) forms of Akt (a kind gift from Dr K Walsh, Tufts University School of Medicine, Boston, MA, USA). In addition, cells were also transduced with recombinant adenoviral vectors expressing full-length p65/RelA or p65/RelA mutant (RelA 1-300) (a kind gift from Dr S Maggiwar, University of Rochester Medical Center, Rochester, NY, USA) used at a multiplicity of infection (MOI) of 50 as previously described [26]. Astrocytes infected for $24 \mathrm{~h}$ with adenoviral constructs were subsequently treated with PDGF-BB, followed by assessment by western blotting or ELISA.

\section{Short interfering RNA transfection of astrocytes}

Short interfering RNA (siRNA) targeted against PDGF$\mathrm{R} \beta$ was obtained from Dharmacon (Boulder, CO, USA). Human A172 cells were plated in 24-well plates at a 
density of $4 \times 10^{4}$ cells per well 1 day prior to transfection. Cell culture medium was replaced with $250 \mathrm{ml}$ pre-warmed OPTI-MEM I culture medium. Lipofectamine2000 reagent (Invitrogen) was then combined with serum-free medium for 5 minutes at room temperature. The PDGF-R $\beta$ siRNA was then added into the mixture described above to a final concentration of $5 \mu \mathrm{M}$. Then, siRNA and the reagent mixture were incubated for 20 minutes at room temperature, after which, the combined mixture was added to the cells. The cell culture plate was shaken gently for $5 \mathrm{~s}$ and incubated for $24 \mathrm{~h}$ at $37^{\circ} \mathrm{C}$. Knockdown efficiency (Figure 1D) of the transfected astrocytes were (54\%) as determined by RT-PCR.

\section{Transfection with plasmid constructs}

DN and WT constructs of MEK were provided by Dr Young Han Lee (Konkuk University, Korea). A172 cells were transfected with plasmid constructs containing either WT or DN forms of MEK as described above. The transfection efficiency was $42 \%$ as determined by immunostaining (data not shown).

\section{ChIP assay}

The ChIP assay was performed according to the manufacturer's instructions (Upstate, Billerica, MA, USA) with slight modifications. After treatment of the cells, $18.5 \%$ fresh formaldehyde was added directly into the medium at a final concentration of $1 \%$ formaldehyde and incubated for 10 minutes at room temperature, followed by quenching with $125 \mathrm{mM}$ glycine. The cells were then scraped using $2 \mathrm{ml}$ pre-chilled PBS containing $1 \times$ protease inhibitor mixture. The cell pellet was harvested by spinning at $800 \mathrm{~g}$ at $4^{\circ} \mathrm{C}$, and lysis buffer was added (provided in the kit) to harvest nuclei. DNA was then sheared by sonication. A total of $50 \mu$ of the sheared crosslinked chromatin was then mixed with $20 \mathrm{ml}$ protein A magnetic beads and $5 \mathrm{mg}$ of immunopreciptating Abs against NFkB p65, acetyl histone H3 (as a positive control), and normal rabbit IgG (as a negative control) diluted in $450 \mathrm{ml}$ dilution buffer overnight at $4^{\circ} \mathrm{C}$. The magnetic beads binding Ab-chromatin complex was then washed with $0.5 \mathrm{ml}$ each of a series of cold wash buffers in the order of low salt buffer, high salt buffer, $\mathrm{LiCl}$ buffer, and Tris-EDTA buffer. The crosslinking of protein-DNA complexes were reversed to free DNA by incubation at $62^{\circ} \mathrm{C}$ for $2 \mathrm{~h}$ and purified using DNA purification spin columns following the manufacturer's instructions. Finally, the purified DNA was amplified (35 cycles) via PCR to identify the promoter region containing NFkB binding site 'GGGCCTTTCC'. The sequence of the primers used to identify the MCP-1 promoter bound to NFkB were as follows: sense: GCATCAGAGC ATTGACCCTCA; antisense: AGGTCAGTGCTGGCG TGAGA.

\section{Monocyte isolation and transmigration}

Primary HBMECs seeded on $6.5 \mathrm{~mm}$ polyester transwell inserts $(5.0 \mu \mathrm{m}$ pore size) were grown to confluence. Following confluency, conditioned media from primary astrocytes treated with PDGF-BB was added to the bottom chamber of the transwell and allowed to incubate at $37^{\circ} \mathrm{C}$ in a humid atmosphere of $5 \% \mathrm{CO}_{2}$ for $24 \mathrm{~h}$. MCP1 neutralizing antibody was added to PDGF-BB treated conditioned media prior to HBMEC exposure for $24 \mathrm{~h}$. Monocytes were obtained from HIV-1, HIV-2 and hepatitis B seronegative donor leukopacks, and separated by countercurrent centrifugal elutriation as previously described [27]. Monocytes were washed with PBS and fluorescently labeled with $10 \mu \mathrm{M}$ Cell tracker green (Invitrogen) for 10 minutes at room temperature. Labeled cells $\left(2 \times 10^{5}\right.$ cells $)$ were added to the upper compartments of transwell inserts and allowed to transmigrate at $37^{\circ} \mathrm{C}$ in a humid atmosphere of $5 \% \mathrm{CO}_{2}$ for $24 \mathrm{~h}$. Transmigrated monocytes were quantified using florescent plate reader (435 nm/528 $\mathrm{nm}$ excitation/emission).

\section{Statistical analysis}

Statistical analysis was performed using one-way analysis of variance (ANOVA) with a post hoc Student's t test. Results were judged statistically significant if $P<0.05$ by analysis of variance.

\section{Results}

HIV-1-mediated upregulation of PDGF-B and MCP-1 in astrocytes

Since astrocytes in the CNS are exposed to HIV-1, we first sought to examine the modulation of PDGF-B and MCP-1 by HIV-1. Purified HIV-1 LAI virus obtained by high-speed ultracentrifugation and resuspended in astrocyte serum-free media was used for these experiments. Serum-starved astrocytes were exposed to purified virus at a MOI of 0.1 for $6 \mathrm{~h}$ followed by assessment of RNA levels by real-time RT-PCR. The MOI of HIV-1 LAI used was based upon our previous study [25]. As shown in Figure 2A, HIV-1 LAI significantly upregulated both PDGF-B (1.7-fold) and MCP-1 (twofold) mRNA levels. To confirm whether increased mRNA levels of PDGF-B translated into increased protein, a western blot analysis was performed on lysates of astrocytes exposed to HIV-1 LAI for $24 \mathrm{~h}$. As shown in Figure 2B exposure to HIV-1 LAI also induced upregulation of PDGF-BB protein. Likewise, supernatants from A172 cells treated with HIV LAI were analyzed for MCP-1 levels via ELISA. As shown in Figure 2D, HIV-1 LAI exposure also resulted in increased MCP-1 levels. To determine whether HIVmediated induction of MCP-1 could, in part, be explained due to increased PDGF-BB levels, astrocytes were treated with the PDGF receptor blocker STI-571 for $1 \mathrm{~h}$ prior to HIV-1 exposure and assessed for MCP-1 

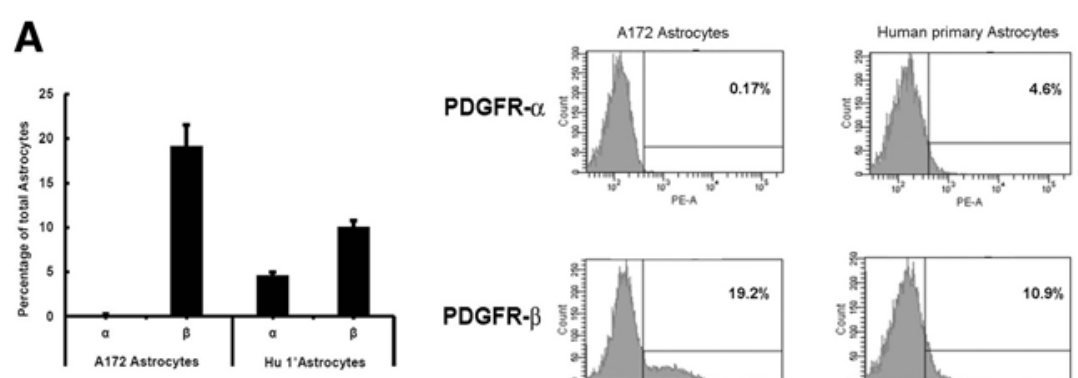

PDGFR- $\beta$
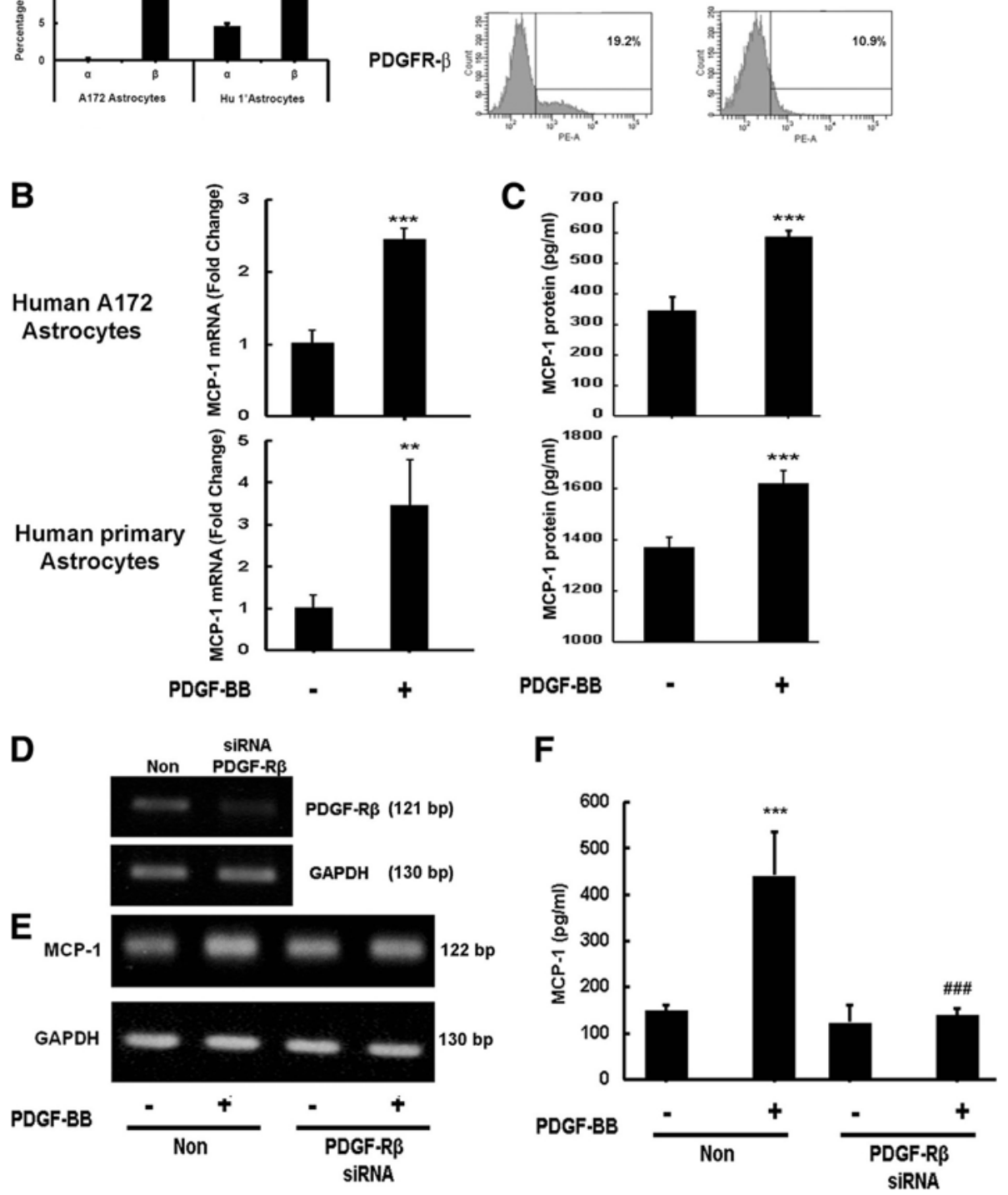

Figure 1 Engagement of platelet-derived growth factor receptor (PDGF-R) is critical for PDGF-BB induced monocyte chemoattractant protein 1 (MCP-1) expression in astrocytes. (A) Human primary as well as A172 primary astrocytes express both PDGF- $\alpha$ and PDGF- $\beta$ receptors. Untreated human primary and A172 astrocytes were subjected to flow cytometric analyses using antibodies against human PDGF-aR (CD140a) and PDGF-BR (CD140ß). (B,C) PDGF-BB-mediated induction of MCP-1 mRNA and protein expression in human primary and A172 astrocytes. (B) Human primary and A172 astrocytes were exposed to PDGF-BB for 6 h. Total RNA isolated from human A172 astrocytes was subjected to real-time reverse-transcriptase polymerase chain reaction (RT-PCR) analysis using primers for human MCP-1. (C) Supernatant fluid from astrocytes treated with PDGF-BB for $24 \mathrm{~h}$ were assessed for release of chemokine MCP-1 using the human MCP-1 enzyme-linked immunosorbent assay (ELISA) kit. (D) Total RNA from A172 cells transfected with either nonsense (Non) or PDGF-R $\beta$ short interfering (si)RNAs was subjected to RT-PCR analysis using primers specific for PDGF-RB. (E) siRNA, but not Non siRNA inhibited PDGF-BB-mediated induction of MCP-1 RNA. (F) Supernatants from A172 cells transfected with either Non or siRNAs were subjected to MCP-1 ELISA assay. PDGF-R $\beta$ siRNA, but not Non siRNA inhibited PDGF-BB-mediated induction of MCP-1 protein. ${ }^{* *} P<0.01$, *** $<0.001$ versus control group. 


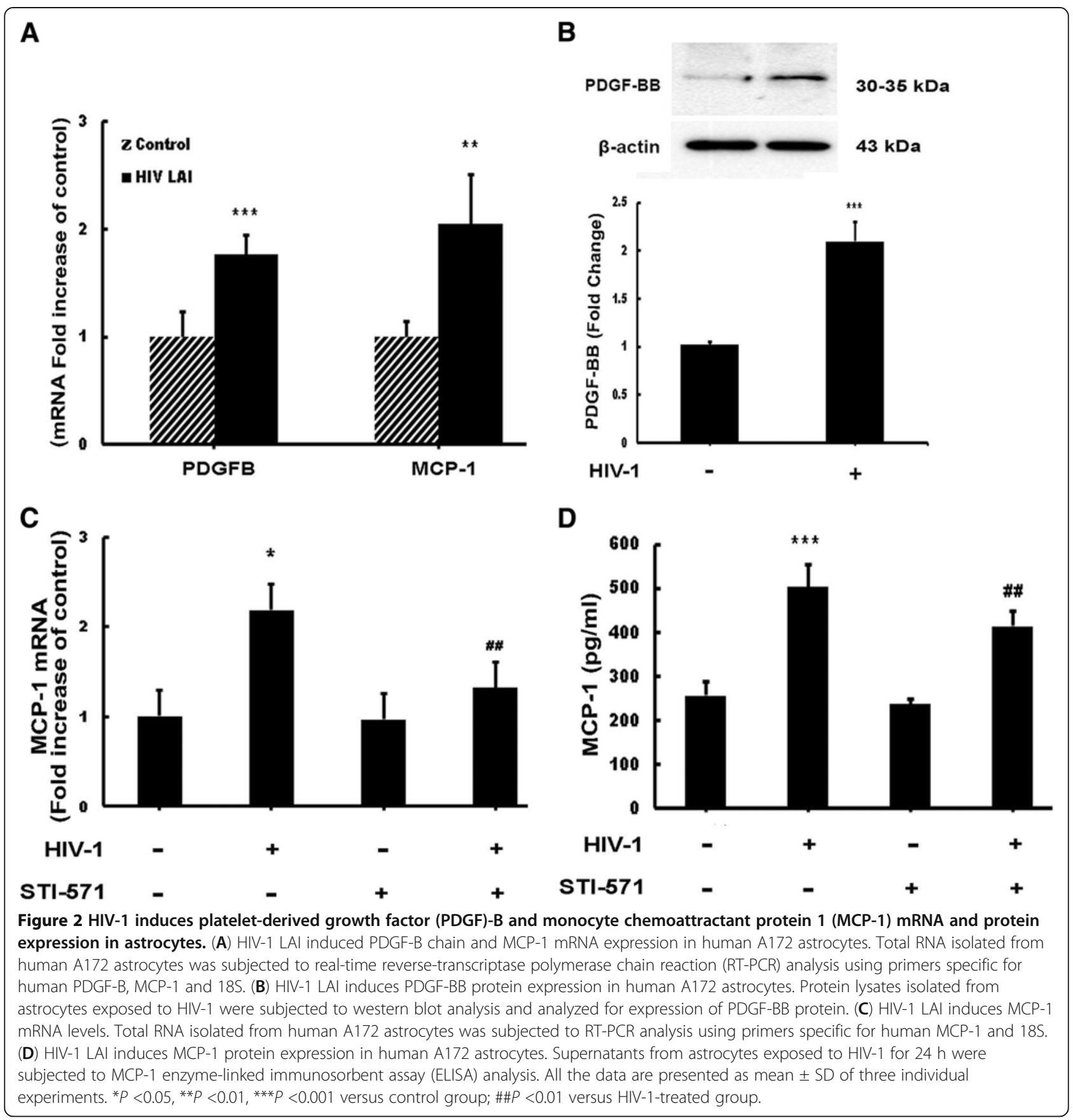

expression. Blocking the PDGF-R significantly reduced HIV-mediated induction of MCP-1 RNA (Figure 2C) and protein (Figure 2D).

PDGF-BB-mediated upregulation of MCP-1 in astrocytes All experiments involving the treatment of cells with exogenous PDGF-BB protein were conducted under serum-free conditions since PDGF promoter is known to have serum response elements $[28,29]$. To investigate the role of PDGF on MCP-1 expression, A172 cells were treated with recombinant PDGF-BB (20 ng/ml) for the indicated times and mRNA levels were assessed by RTPCR and real-time RT-PCR. The concentration of PDGF-BB used was based on previous studies [25,30]. Following exposure of A172 astrocytes to PDGF-BB, there was a time-dependent upregulation of MCP-1 mRNA compared with untreated cells (Figure 3A) with a peak induction at $6 \mathrm{~h}$ post treatment (4.5-fold) and a subsequent downregulation at $12 \mathrm{~h}$. Similar results were obtained via real-time PCR (Figure 3B).

To determine whether the increased MCP-1 mRNA expression correlated with increased protein release in 


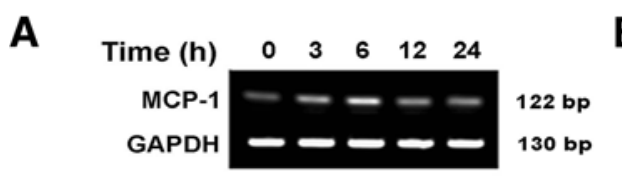

\section{B}
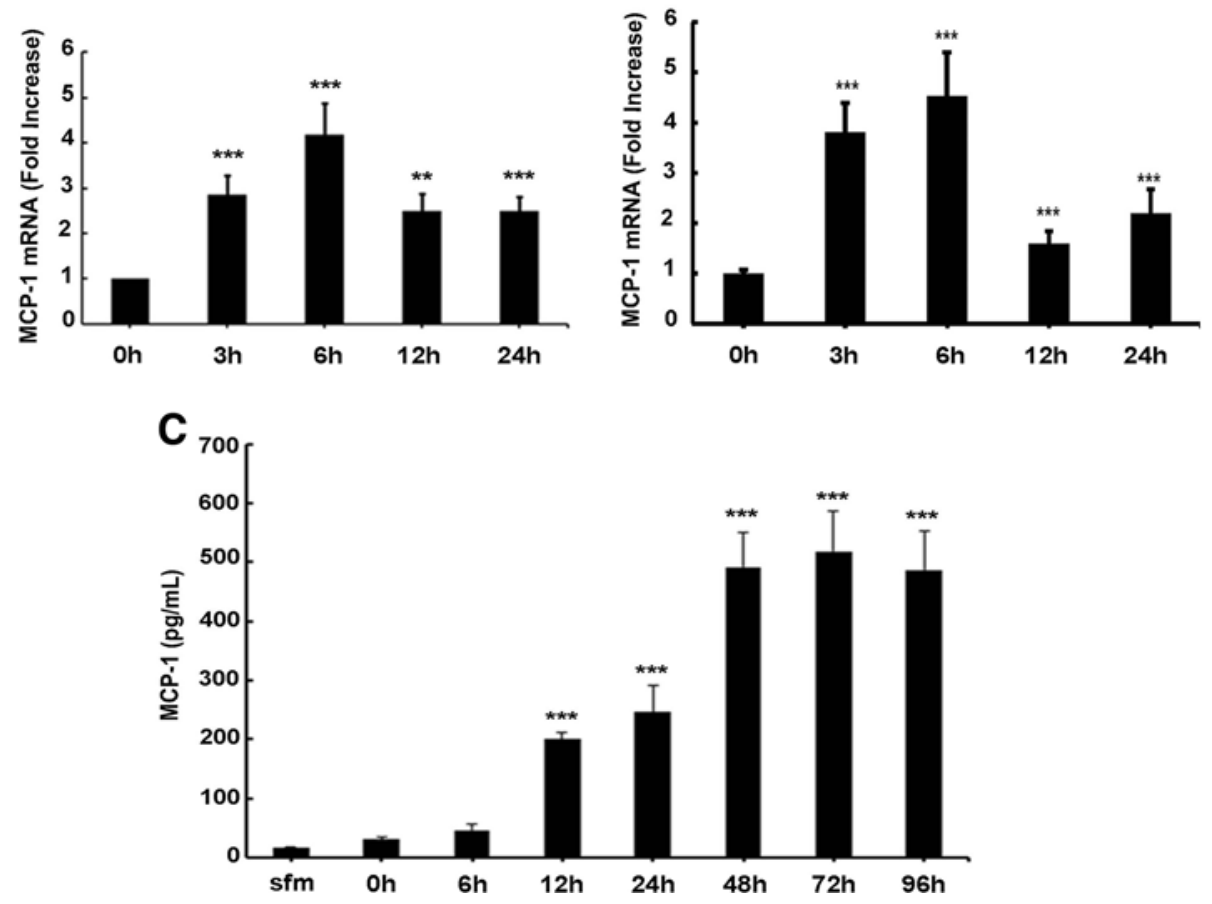

Figure 3 Platelet-derived growth factor (PDGF)-BB induces monocyte chemoattractant protein 1 (MCP-1) mRNA and protein expression in human astrocytes. $(\mathbf{A}, \mathbf{B})$ Time-dependence of PDGF-BB-mediated induction of MCP-1 mRNA expression in human A172 astrocytes. Total RNA isolated from human $\mathrm{A} 172$ astrocytes was subjected to reverse-transcriptase polymerase chain reaction (RT-PCR) and real-time RT-PCR analysis using primers for human MCP-1 and glyceraldehyde-3-phosphate dehydrogenase (GAPDH) and 18S, respectively. PDGF-BB-mediated induction of MCP-1 mRNA expression peaked at $6 \mathrm{~h}$ and decline thereafter. (C) Time-dependence of PDGF-BB-mediated induction of MCP-1 protein expression in human A172 astrocytes. Supernatant fluid from human A172 cells treated with PDGF-BB for various time points were assessed for release of chemokine MCP-1 using the human MCP-1 enzyme-linked immunosorbent assay (ELISA) kit. PDGF-BB treatment resulted in a timedependent induction of MCP-1 expression. All the data are presented as mean \pm SD of three individual experiments. ${ }^{* *} P<0.01,{ }^{* * *} P<0.001$ versus control group; sfm = serum-free media.

astrocytes, we next examined the MCP-1 protein levels. Cells were serum-starved as described and treated with PDGF-BB for 0 to $96 \mathrm{~h}$. Supernatant fluids were collected and MCP-1 protein levels were assessed by ELISA. As shown in Figure 3C, PDGF-BB upregulated MCP-1 protein levels in a time-dependent manner with a continual increase that plateaued at $48 \mathrm{~h}$ post treatment. Cumulatively, these data clearly demonstrate that PDGF-BB treatment mediated the induction of MCP-1 RNA and protein in astrocytes.

\section{Engagement of PDGF-R $\beta$ is critical for PDGF-induced MCP-1 expression in astrocytes}

Because PDGF-BB mediates its effects via binding to its cognate receptors PDGF-R $\alpha$ and PDGF-R $\beta$, our next step was to examine the role of receptor binding in PDGF-BB-induced MCP-1 release by astrocytes. However, before proceeding with this, it was important to first examine whether astrocytes indeed expressed PDGF-R $\alpha$ and PDGF-R $\beta$. Flow cytometric analysis of A172 and human primary astrocytes revealed a stark difference between the two types of cells. As shown in Figure $1 \mathrm{~A}$, of the A172 cells examined, endogenous levels of PDGF-R $\alpha$ and PDGF-R $\beta$ were $0.17 \%$ and $19.2 \%$, respectively. Human primary astrocytes expressed higher levels of PDGF-R $\alpha$ (4.6\%) and lower PDGF-R $\beta$ (10.9\%) levels compared to A172 astrocytes. Despite the difference in relative distribution of the PDGF receptors, PDGF-R $\beta$ was the major receptor form expressed in both types of astrocytes utilized in this study. Similar results were observed by RT-PCR (data not shown).

Having determined the relative expressions of PDGFRs in both human primary and A172 astrocytes, we next sought to confirm the effect of PDGF-BB on MCP-1 release in both cells types. Astrocytes were exposed to PDGF-BB for $6 \mathrm{~h}$ and $24 \mathrm{~h}$ for mRNA and protein 
assessment, respectively. As shown in Figure 1B, PDGFBB upregulated MCP-1 mRNA levels in both human A172 as well as human primary astrocytes. MCP-1 protein ELISA analysis also corroborated this upregulation, as shown in Figure $1 \mathrm{C}$.

To determine the role that the PDGF-Rs played in PDGF-BB-mediated MCP-1 release from astrocytes, human A172 astrocytes were transfected with PDGF-R $\beta$ siRNA followed by treatment of PDGF-BB and MCP-1 levels were assessed $24 \mathrm{~h}$ later. As shown in Figure 1D, transfection of human A172 cells with PDGF-R $\beta$ siRNA resulted in efficient knockdown of PDGF-R $\beta$ as demonstrated by RT-PCR. Cells were transfected with either PDGF-R $\beta$ siRNA or non-specific (Non) siRNA control followed by treatment with PDGF-BB for $24 \mathrm{~h}$. PDGFBB-mediated induction of MCP-1 mRNA was attenuated in cells transfected with PDGF-R $\beta$ siRNA but not in the Non siRNA controls cells (Figure 1E). These results were further confirmed by examining PDGF-BB-mediated induction of MCP-1 protein levels. As shown in Figure $1 \mathrm{~F}$ and as expected, PDGF-BB treatment resulted in enhanced release of MCP-1 protein in Non siRNA transfected cells but not in cells transfected with PDGF-R $\beta$ siRNA. Taken together, these findings confirmed the involvement of PDGF-Rs in PDGF-BB-mediated induction of MCP-1 in astrocytes.

\section{PDGF-BB-mediated induction of MCP-1 involves MAPK and $\mathrm{PI} 3 \mathrm{~K} / \mathrm{Akt}$ cell signaling pathways}

Having determined PDGF-BB-mediated induction of MCP-1, we next sought to elucidate the signaling pathways involved in this process. Since PDGF-BB is a mitogen and a pro-survival protein, we examined the involvement of MAPK and phosphoinositide-3-kinase/ Akt pathways. Human A172 cells were exposed to PDGF-BB and phosphorylation of MAPK and PI3K/Akt signaling molecules was assessed by western blotting. Treatment of astrocytes with PDGF-BB resulted in a time-dependent increase in phosphorylation of ERK1/2, JNK, p38 and Akt, with maximal activation at 30 minutes following treatment (Figure 4A). Next, to address the functional implication of MAPK and PI3K/Akt pathways in PDGF-mediated induction of MCP-1 expression, A172 cells were pretreated with inhibitors specific for the respective signaling pathways followed by PDGF-BB treatment for $24 \mathrm{~h}$ and subsequently assessed for expression of MCP-1. As shown in Figure 4B, treatment of cells with the MAPK and PI3K/Akt inhibitors resulted in amelioration of PDGF-BB-mediated induction of MCP-1 protein levels.

Further validation of the involvement of the MAPK pathway in this process was confirmed by transfecting cells with either the WT or DN constructs of MEK followed by $24 \mathrm{~h}$ treatment with PDGF-BB. PDGF-BB- mediated induction of MCP-1 was attenuated by DNMEK, but not by WT-MEK constructs (Figure 4C). To confirm the role of PI3K/Akt in PDGF-BB-mediated MCP-1, A172 cells were transduced with adenoviral constructs containing either WT or DN forms of Akt. As shown in Figure 4D, cells transduced with DN Akt construct failed to upregulate MCP-1 unlike the cells transduced with the WT Akt construct. Taken together, these findings confirm the involvement of both MAPK and PI3K/Akt cascades in PDGF-BB-mediated induction of MCP-1 in astrocytes.

\section{Involvement of PDGF-R $\beta$ in the regulation of MAPKs and $\mathrm{PI} 3 \mathrm{~K} /$ Akt cell signaling pathways}

Since PDGF-BB acts through its cognate receptor, the next logical step was to link the MAPK and PI3K/Akt pathways to PDGF-R. To achieve this, siRNA was again employed. PDGF-R $\beta$ expression was knocked down using the siRNA approach and ERK, JNK, p38, JNK and Akt phosphorylation levels were assessed. Briefly, A172 cells were transfected with PDGF-R $\beta$ siRNA for $24 \mathrm{~h}$ followed by treatment with PDGF-BB for $1 \mathrm{~h}$. As shown in Figure $5 \mathrm{~A}, \mathrm{~B}$, cells transfected with PDGF-R $\beta$ siRNA failed to demonstrate PDGF-BB-mediated activation of ERK, JNK, p38 and Akt. These results underpin the role of PDGF-R $\beta$ in PDGF-BB-mediated activation of MAPK and PI3K/Akt pathways.

\section{Involvement of NFKB in PDGF-BB-induced expression of MCP-1 in astrocytes}

Having determined the role of MAPK and PI3K/Akt in PDGF-BB-mediated induction of MCP-1 expression, we rationalized the involvement of $\mathrm{NF} \mathrm{B}$ in this process since this transcription factor is downstream of the aforementioned signaling mediators [31-33]. Exposure of astrocytes to PDGF-BB resulted in a time-dependent increase of p65 subunit of $N F \kappa B$ in the nucleus with a concomitant transient increase in cytosolic $\mathrm{pI \kappa B}$ (Figure 6A). Validation of the role of $N F k B$ was further determined by pretreating astrocytes with the IkB pathway inhibitor (SC514), followed by PDGF-BB treatment for $24 \mathrm{~h}$. As shown in Figure 6B, SC514 inhibited PDGF$\mathrm{BB}$-mediated induction of $\mathrm{MCP}-1$, thereby underscoring the role of $\mathrm{NF} \mathrm{B}$ in this process.

To corroborate the findings found using the pharmacological inhibitors these cells were then transduced with either WT or DN adenoviral constructs of NFKB. As shown in Figure $6 \mathrm{C}$, transduction with $\mathrm{DN}$ form of $\mathrm{NF} K \mathrm{~B}$ resulted in inhibition of PDGF-BB-mediated induction of MCP-1. Transduction with the WT NFKB construct, however, and as expected, demonstrated PDGF-BB-mediated induction of MCP-1. Together, these findings underpin the role of $\mathrm{NF} \mathrm{BB}$ in PDGF-BBmediated induction of MCP-1 in astrocytes. 

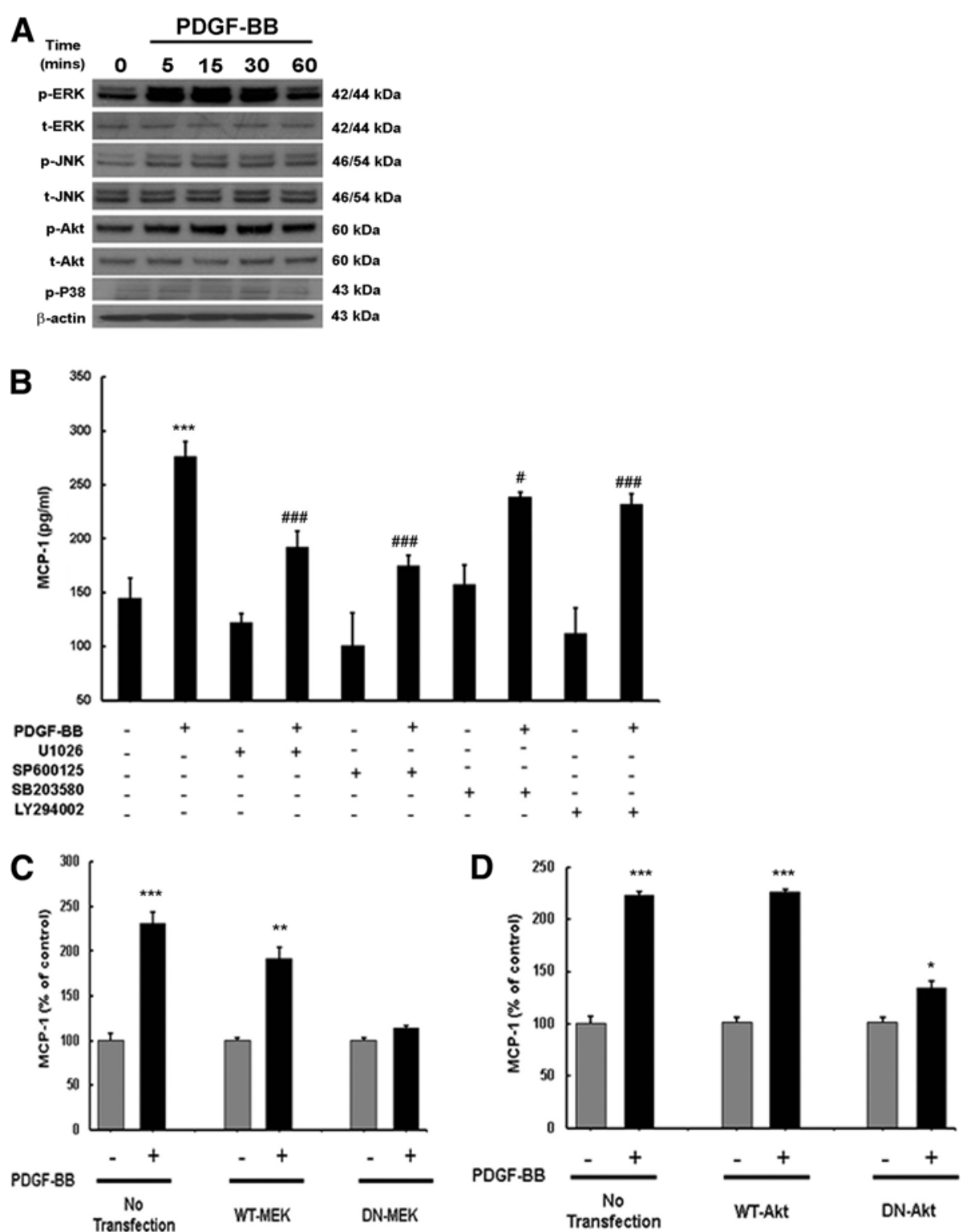

Figure 4 Platelet-derived growth factor (PDGF)-BB-mediated induction of monocyte chemoattractant protein 1 (MCP-1) expression involves mitogen-activated protein kinases (MAPKs) and phosphatidylinositol 3-kinase (PI3K)/Akt cell signaling pathways. (A) Western blot analysis of time-dependent activation of extracellular-signal-regulated kinase (ERK), c-Jun N-terminal kinase (JNK), P38 and Akt by PDGF-BB. (B) Inhibition of the ERK, JNK, p38 and Akt pathways by mitogen-activated protein (MAP) kinase kinase (MEK)1/2 (U0126), JNK (SP600125), p38 (SB20358) and PI3K (LY294002) inhibitors resulted in amelioration of PDGF-BB-mediated induction of MCP-1 expression in astrocytes. (C) Transfection with dominant-negative (DN)-MEK but not wild-type (WT)-MEK resulted in abrogation of PDGF-BB-mediated induction of MCP-1. (D) Transduction with DN-Akt but not WT-Akt also resulted in abrogation of PDGF-BB-mediated induction of MCP-1. All the data are presented as mean $\pm \mathrm{SD}$ of three individual experiments. ${ }^{*} P<0.05$, ${ }^{* *} P<0.01,{ }^{* * *} P<0.001$ versus control group; $\# P<0.05$, \#\#\# $<0.001$ versus PDGF-BB-treated group.

Since NFkB is a transcription factor that mitigates its effects on target genes by binding to promoter regions, we next sought to confirm the binding of $\mathrm{NFKB}_{\mathrm{K}}$ with MCP-1 promoter in its natural chromatin context by ChIP assay to reveal active sites accessible to NFKB. A172 cells were treated with PDGF-BB for $1 \mathrm{~h}$ followed by RNA extraction and processed using a ChIP analysis kit. These experiments revealed increased binding of $\mathrm{NF} \kappa \mathrm{B}$ to the MCP-1 promoter in A172 cells treated with PDGF-BB (Figure 6D,E) and, along with preceding data, substantiate the role of NFKB in PDGF-BB-mediated regulation of MCP-1 in astrocytes. 


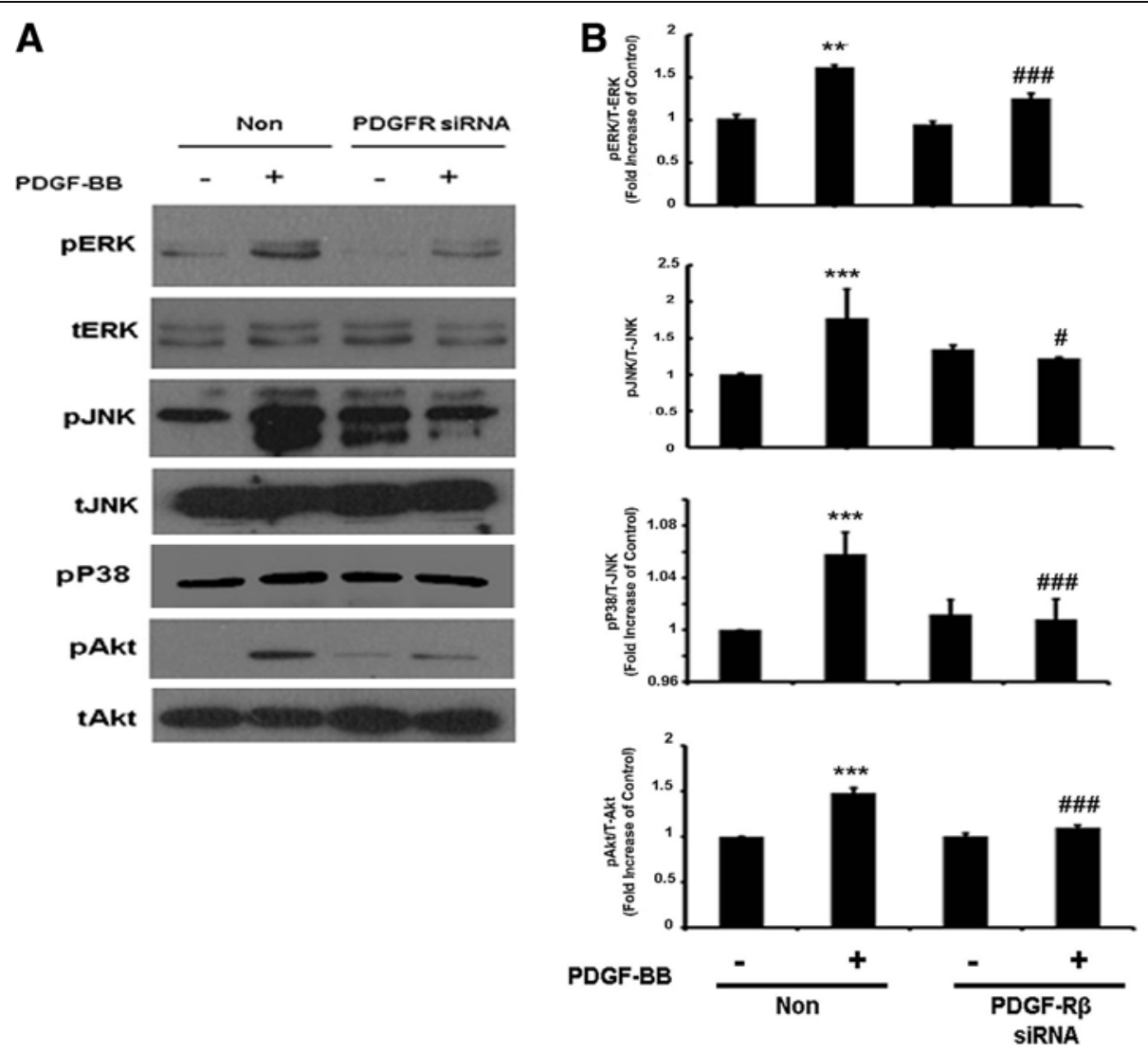

Figure 5 Involvement of platelet-derived growth factor (PDGF)-R $\beta$ in the regulation of mitogen-activated protein kinases (MAPKs) and phosphatidylinositol 3-kinase (PI3K)/Akt cell signaling pathways. (A) Whole cell lysates from A172 cells transfected with either nonsense (Non) or PDGF-Rß short interfering (si)RNAs were subjected to immunoblot analysis using antibodies specific for MAPKs and PI3K/Akt signaling. PDGF-Rß siRNA, but not Non siRNA inhibited PDGF-BB-mediated phosphorylation of extracellular-signal-regulated kinase (ERK), c-Jun N-terminal kinase (JNK), p38 and Akt pathways. All the data are presented as mean \pm SD of three individual experiments. ${ }^{* *} P<0.01,{ }^{* * *} P<0.001$ versus control group, \#\#P<0.01, \#\#\#<0.001 versus PDGF-BB-treated group.

MAPK and PI3K/Akt cell signaling pathways lie upstream of PDGF-BB induced NFKB in astrocytes

Having determined the involvement of ERK1/2, JNK and p38 MAPKs and NFKB in PDGF-BB-mediated MCP-1 the next logical step was to examine whether there existed a link that could tie together the activation of MAP kinase and Akt pathways with NFkB. Astrocytes were transfected with either the WT or DN constructs of MEK prior to PDGF-BB treatment as described before. Nuclear fractions were extracted and NFKB phosphorylation was assessed via western blotting. PDGFBB-mediated induction of $\mathrm{NF}_{\mathrm{K}} \mathrm{B}$ was attenuated by $\mathrm{DN}$ MEK, but not by WT-MEK construct (Figure 7A). To confirm the role of PI3K/Akt in PDGF-BB-mediated NFKB, A172 cells were transduced with adenoviral constructs containing either WT or DN forms of Akt, treated with PDGF-BB and assessed for NFkB expression. As shown in Figure 7B, cells transduced with DN Akt construct failed to upregulate $\mathrm{NF}_{\kappa} \mathrm{B}$ unlike the cells transduced with the WT Akt construct. These findings thus linked PDGF-BB-mediated activation of MAP kinase and Akt pathways to the downstream activation of NFKB.

\section{MCP-1 released from astrocytes increases monocyte} transmigration in human brain microvascular endothelial cells

Having determined the induction of MCP-1 by PDGF$\mathrm{BB}$, the next step was to explore the functional relevance of this upregulation. Since MCP-1 is a known chemoattractant, we hypothesized that PDGF-BB-induced MCP-1 released from the astrocytes could, in fact, act on neighboring endothelial cells altering their function. Human astrocytes were exposed to PDGF-BB for $2 \mathrm{~h}$ then replaced with fresh media and incubated for $24 \mathrm{~h}$. Endothelial cells were grown on the upper compartment of transwell plates and spent media was added to the lower compartment overnight. Labeled human monocytes were added to the upper compartment for $24 \mathrm{~h}$ and monocyte transmigration was assessed. As shown in Figure 8, conditioned media from primary astrocytes 
A
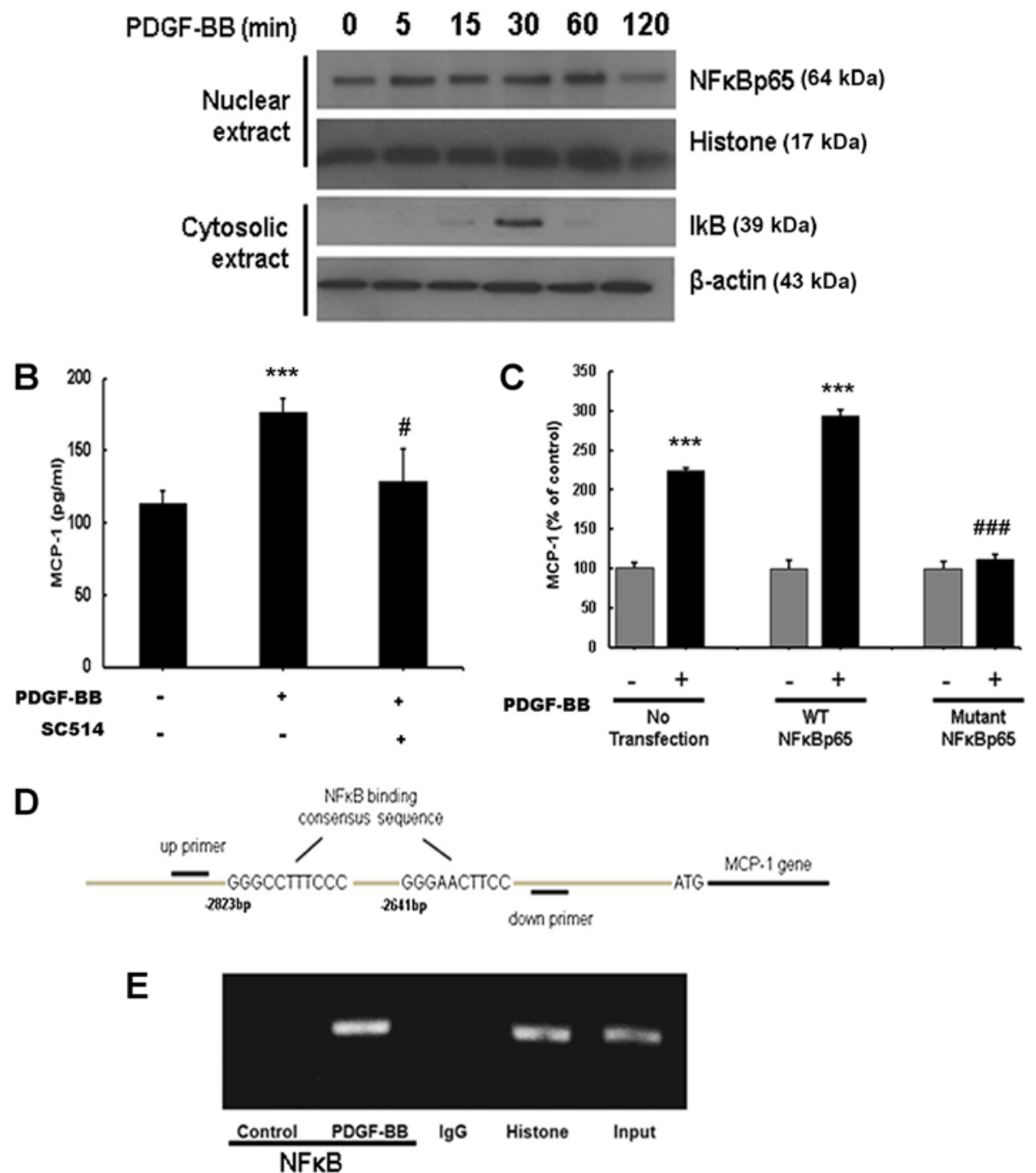

Figure 6 Platelet-derived growth factor (PDGF)-BB-mediated induction of monocyte chemoattractant protein 1 (MCP-1) expression involves nuclear factor $\mathbf{K B}$ (NFKB) activation. (A) Exposure of A172 cells to PDGF-BB resulted in a time-dependent increase in phosphorylation of the p65 subunit of NFKB in the nuclear cellular fraction. Reciprocally, PDGF-BB exposure resulted in a time-dependent increase in inhibitor of $\mathrm{KBa}(\mathrm{I} \mathrm{KBa})$ phosphorylation in the cytosolic cellular fraction of A172 astrocytes. (B) Pretreatment with the IKBa inhibitor, SC514 resulted in inhibition of PDGF-BB-mediated induction of MCP-1. (C) Transduction with mutant-NFKB but not wild-type (WT)-NFKB resulted in abrogation of PDGF-BB-mediated induction of MCP-1. All the data are presented as mean \pm SD of three individual experiments. ${ }^{* *} P<0.001$ versus control group, \#P<0.05, \#\#\#<0.001 versus PDGF-BB-treated group. (D) Schematic illustration of NFkB binding consensus sequence on the promoter region of MCP-1. (E) Chromatin immunoprecipitation (ChIP) assay demonstrating PDGF-BB-mediated binding of p65NFKB to the MCP-1 promoter.

cells treated with PDGF-BB resulted in a significant increase in monocyte transmigration of endothelial cells, an effect that was blocked by PDGF-R blocker STI-571.

Since monocytes express the MCP-1 receptor CCR2 $[34,35]$, the next step was to determine whether increased MCP-1 was also able to enhance monocyte migration. Also shown in Figure 8A, conditioned media from primary astrocytes cells treated with PDGF-BB resulted in a dramatic increase in monocyte transmigration of endothelial cells and this effect was ameliorated in conditioned media treated with the MCP-1 neutralizing antibody. These findings thus confirm that MCP-1 was involved in PDGF-BB-mediated disruption of the endothelial barrier permeability and not only underpin the role of MCP-1 in BBB breakdown, but reveal a vital role that activated astrocytes play in BBB disruption and HAND pathogenesis.

\section{Discussion}

Antiretroviral therapies have proven highly effective in controlling systemic viral infection, thus leading to increased longevity in patients with AIDS. The inability 
A
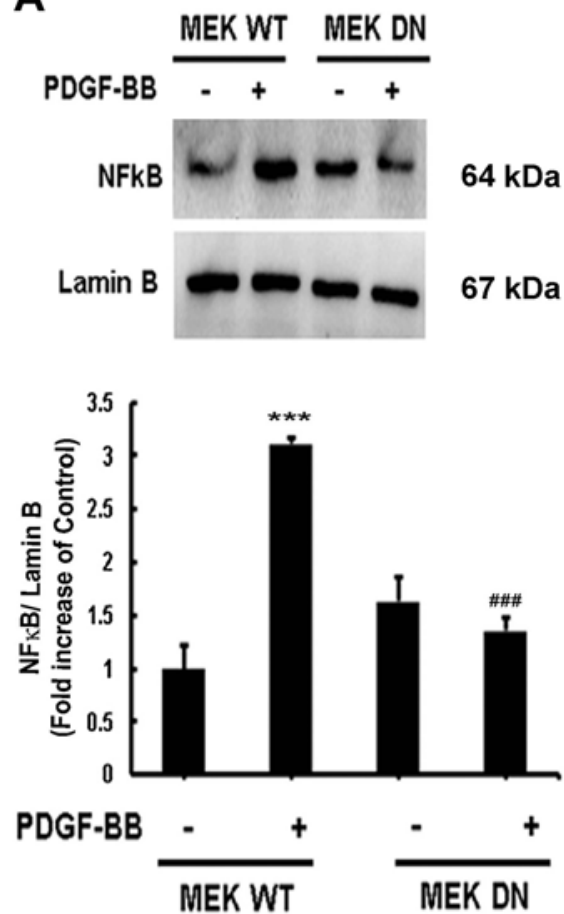

B

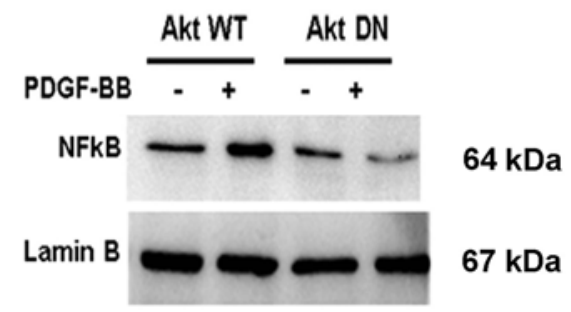

Figure 7 Mitogen-activated protein kinase (MAPK) and phosphatidylinositol 3-kinase (PI3K)/Akt cell signaling pathways lie upstream of platelet-derived growth factor (PDGF)-BB induced nuclear factor KB (NFKB) in astrocytes. The nuclear fractions of A172 cells transfected with wild-type (WT) or dominant-negative (DN) forms of mitogen-activated protein (MAP) kinase kinase (MEK) and Akt were subjected to western blot analysis for NFKB. (A) Transfection with DN-MEK but not WT-MEK resulted in abrogation of PDGF-BB-mediated induction of NFKB phosphorylation. (B) Transduction with DN-Akt but not WT-Akt also resulted in abrogation of PDGF-BB-mediated induction of NFKB phosphorylation. All the data are presented as mean \pm SD of three individual experiments. ${ }^{* *} P<0.001$ versus control group, \#\#\#P<0.001 versus PDGF-BB-treated group.

of some of these drugs to cross the BBB results in slow and smoldering infection in the CNS. Subsequently, the brain becomes a sanctuary of virus-induced toxicity leading to increased prevalence of HAND in HIVinfected individuals. One of the hallmark features of HAND is increased astrogliosis comprising of increased numbers of activated astrocytes, culminating ultimately into increased neuronal degeneration. It is well recognized that activation of astrocytes leads to the release of a barrage of inflammatory mediators such as PDGF-BB. PDGF-BB has been implicated in a variety of pathological conditions; however, its role in HIV pathogenesis remains less clear.

In the present study we demonstrate that HIV-1mediated induction of MCP-1, a potent chemokine vital to the sustained proinflammatory response in HIV-1 pathogenesis, is regulated by PDGF-BB. To determine the implication of increased PDGF-BB we demonstrated that PDGF-BB treatment of human astrocyte cell line and primary cultures resulted in induction of MCP-1 and this process was mediated via the binding of PDGF$\mathrm{BB}$ to its cognate PDGF-R $\beta$. These findings are consistent with the reports on PDGF-mediated induction of
MCP-1 in other cell types such as the fibroblast cell line and smooth muscle cells [36,37]. In our efforts to dissect the upstream signaling events that are involved in MCP1 release from astrocytes, using both the pharmacological as well as genetic approaches we demonstrated the role of MAPK and PI3K/Akt in PDGF-BB-mediated induction of MCP-1 from astrocytes. The involvement of MAPK and PI3K/Akt pathways in the induction of MCP-1 expression are in agreement with the role these pathways play in induction of this chemokine in other cell types including osteoblasts, mesangial cells and endothelial cells [38-40]. The transcription factor, $\mathrm{NF \kappa B}$ is known to play a key role in PDGF-BB signaling and also in the expression of proinflammatory cytokines/ chemokines including MCP-1 [31,33,41]. Consistent with other reports, our studies also revealed that PDGF-BBmediated induction of MCP-1 involved both NFKB activation and its binding to the MCP-1 promoter.

It was next of interest to explore the functional relevance of PDGF-BB-mediated induction of MCP-1. Based on the proximity of astrocytes to the endothelial barrier, we rationalized that induced expression of MCP-1 in PDGF-BB treated astrocytes could play a role in barrier 


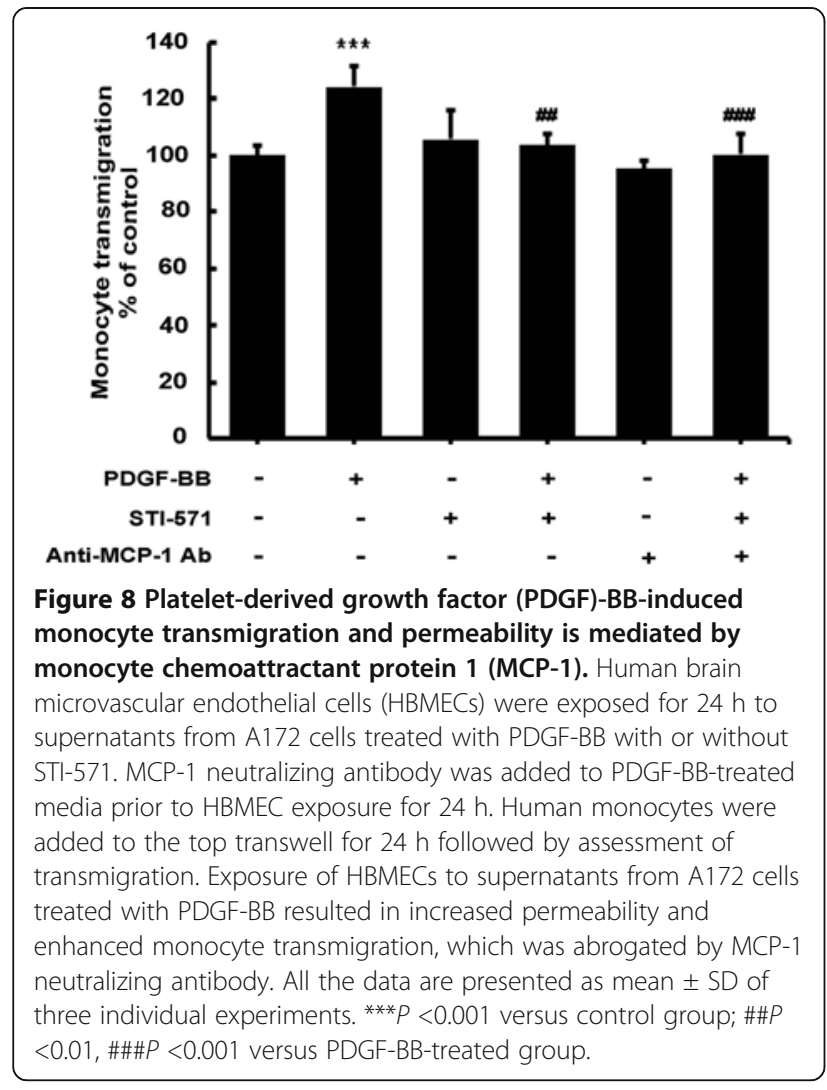

integrity. Intriguingly, conditioned media from PDGF$\mathrm{BB}$ treated astrocytes did indeed increase monocyte transmigration and this effect was attributable to MCP-1 as demonstrated in the blocking antibody experiments. This role of MCP-1 is in agreement with the findings reported by Eugenin et al. who have demonstrated that HIV-infected leukocyte transmigration across a tissue culture model of human BBB involved MCP-1 [42]. In addition to disrupting the barrier permeability, MCP-1 also manifested increased monocyte recruitment. This latter function is in keeping with its known roles both as a chemoattractant and as a biomarker of HIV neuropathogenesis $[42,43]$.

The function of MCP-1 demonstrated in this study can have ramifications in the pathogenesis of HAND. Based on the proximity of astrocytes to the endothelium and their ability to secrete both PDGF-BB and the chemokine MCP-1 as well as their abundance in the CNS, it can be argued that during HIV-1 infection, viral proteins can initiate a toxic cascade that can be self-perpetuating. HIV-1/HIV-1 Tat can trigger increased expression of PDGF-BB, which in turn, can lead to increased MCP-1 expression that can manifest as an amplified influx of monocytes into the CNS. PDGF-BB has already been shown to disrupt the BBB [19] and a similar function has been demonstrated for MCP-1 [42]. Therefore the release of both these mediators can independently disrupt the endothelial barrier while enhancing neuroinflammation $[19,42]$, which can have serious ramifications in HAND.

In summary, our studies have mapped out a detailed molecular pathway of PDGF-BB-mediated MCP-1 expression in astrocytes involving ERK1/2, JNK MAPK activation, with the subsequent activation of $\mathrm{NFKB}$ resulting in increased MCP-1 expression, ultimately leading to increased monocyte transmigration and increased permeability in the brains of individuals infected with HIV.

\section{Competing interests}

The authors declare that they have no competing interests.

\section{Authors' contributions}

CB-B designed research, performed research and wrote the manuscript; $H Y$ designed the research and wrote the manuscript; GH performed research; SB planned and designed the research and wrote the manuscript. All authors have read and approved the final version of the manuscript.

\section{Acknowledgements}

We thank Dr Randall Davis (Oklahoma State University, Stillwater, OK, USA) for providing the A172 cell line and Dr Monique Stins (Johns Hopkins University, Baltimore, MD, USA) for providing the HBMECs. We thank Dr Howard Gendelman (University of Nebraska Medical Center, Omaha, NE, USA) for providing us the HIV-1 LAI. We thank Dr Sanjay Maggirwar (University of Rochester Medical Center, Rochester, NY, USA) for providing us with recombinant adenovirus vectors of full-length RelA and mutant RelA. We also thank Dr Young Han Lee (Konkuk University, Korea) for providing the constitutively active and dominant-negative constructs of MEK and Dr K Walsh (Tufts University School of Medicine, Boston, MA, USA) for providing the adenoviral vectors expressing the WT and DN forms of Akt.

\section{Author details}

'Department of Pharmacology and Experimental Neuroscience, University of Nebraska Medical Center, Omaha, NE 68198, USA. ²Department of Medical Microbiology and Immunology, Creighton Medical Center, Omaha, NE 68178, USA. ${ }^{3}$ Department of Pharmacology and Experimental Neuroscience, 985880 Nebraska Medical Center (DRC 8011), University of Nebraska Medical Center, Omaha, NE 68198-5880, USA.

Received: 29 March 2012 Accepted: 15 November 2012

Published: 1 December 2012

\section{References}

1. Heaton RK, Clifford DB, Franklin DR Jr, Woods SP, Ake C, Vaida F, Ellis RJ, Letendre SL, Marcotte TD, Atkinson JH, Rivera-Mindt M, Vigil OR, Taylor MJ, Collier AC, Marra CM, Gelman BB, McArthur JC, Morgello S, Simpson DM, McCutchan JA, Abramson I, Gamst A, Fennema-Notestine C, Jernigan TL, Wong J, Grant I, CHARTER Group: HIV-associated neurocognitive disorders persist in the era of potent antiretroviral therapy: CHARTER Study. Neurology 2010, 75:2087-2096.

2. Weiss JM, Nath A, Major EO, Berman JW: HIV-1 Tat induces monocyte chemoattractant protein-1-mediated monocyte transmigration across a model of the human blood-brain barrier and up-regulates CCR5 expression on human monocytes. J Immunol 1999, 163:2953-2959.

3. Fuentes ME, Durham SK, Swerdel MR, Lewin AC, Barton DS, Megill JR, Bravo R, Lira SA: Controlled recruitment of monocytes and macrophages to specific organs through transgenic expression of monocyte chemoattractant protein-1. J Immunol 1995, 155:5769-5776.

4. Lee SC, Liu W, Dickson DW, Brosnan CF, Berman JW: Cytokine production by human fetal microglia and astrocytes. Differential induction by lipopolysaccharide and IL-1 beta. J Immunol 1993, 150:2659-2667.

5. Rock RB, Hu S, Sheng WS, Peterson PK: Morphine stimulates CCL2 production by human neurons. J Neuroinflammation 2006, 3:32.

6. Ransohoff RM, Hamilton TA, Tani M, Stoler MH, Shick HE, Major JA, Estes ML, Thomas DM, Tuohy VK: Astrocyte expression of mRNA encoding 
cytokines IP-10 and JE/MCP-1 in experimental autoimmune encephalomyelitis. FASEB J 1993, 7:592-600.

7. Mahad DJ, Ransohoff RM: The role of MCP-1 (CCL2) and CCR2 in multiple sclerosis and experimental autoimmune encephalomyelitis (EAE). Semin Immunol 2003, 15:23-32.

8. Van Der Voorn P, Tekstra J, Beelen $\mathrm{RH}$, Tensen $\mathrm{CP}$, Van Der Valk $\mathrm{P}$ De Groot CJ: Expression of MCP-1 by reactive astrocytes in demyelinating multiple sclerosis lesions. Am J Pathol 1999, 154:45-51.

9. Tanuma N, Sakuma H, Sasaki A, Matsumoto Y: Chemokine expression by astrocytes plays a role in microglia/macrophage activation and subsequent neurodegeneration in secondary progressive multiple sclerosis. Acta Neuropathol 2006, 112:195-204.

10. Berman JW, Guida MP, Warren J, Amat J, Brosnan CF: Localization of monocyte chemoattractant peptide-1 expression in the central nervous system in experimental autoimmune encephalomyelitis and trauma in the rat. J Immunol 1996, 156:3017-3023.

11. Yamamoto M, Horiba M, Buescher JL, Huang D, Gendelman HE, Ransohoff RM, Ikezu T: Overexpression of monocyte chemotactic protein-1/CCL2 in beta-amyloid precursor protein transgenic mice show accelerated diffuse beta-amyloid deposition. Am J Pathol 2005, 166:1475-1485.

12. Marks SD, Shah V, Pilkington C, Tullus K: Urinary monocyte chemoattractant protein-1 correlates with disease activity in lupus nephritis. Pediatr Nephrol 2010, 25:2283-2288.

13. Groh J, Heinl K, Kohl B, Wessig C, Greeske J, Fischer S, Martini R: Attenuation of MCP-1/CCL2 expression ameliorates neuropathy in a mouse model for Charcot-Marie-Tooth 1X. Hum Mol Genet 2010, 19:3530-3543.

14. Andrae J, Gallini R, Betsholtz C: Role of platelet-derived growth factors in physiology and medicine. Genes Dev 2008, 22:1276-1312.

15. Kohler N, Lipton A: Platelets as a source of fibroblast growth-promoting activity. Exp Cell Res 1974, 87:297-301.

16. Ross R, Glomset J, Kariya B, Harker L: A platelet-dependent serum factor that stimulates the proliferation of arterial smooth muscle cells in vitro. Proc Natl Acad Sci U S A 1974, 71:1207-1210.

17. Bowen-Pope DF, Malpass TW, Foster DM, Ross R: Platelet-derived growth factor in vivo: levels, activity, and rate of clearance. Blood 1984, 64:458-469.

18. Su EJ, Fredriksson L, Geyer M, Folestad E, Cale J, Andrae J, Gao Y, Pietras K, Mann K, Yepes M, Strickland DK, Betsholtz C, Eriksson U, Lawrence DA: Activation of PDGF-CC by tissue plasminogen activator impairs blood-brain barrier integrity during ischemic stroke. Nat Med 2008, 14:731-737.

19. Yao H, Duan M, Buch S: Cocaine-mediated induction of platelet-derived growth factor: implication for increased vascular permeability. Blood 2011, 117:2538-2547

20. Davis RL, Dertien J, Syapin PJ: Ethanol-induced modulation of inducible nitric-oxide synthase activity in human A172 astrocytoma cells. Alcohol Clin Exp Res 2002, 26:1404-1411.

21. Yao H, Kim K, Duan M, Hayashi T, Guo M, Morgello S, Prat A, Wang J, Su TP, Buch S: Cocaine hijacks sigma1 receptor to initiate induction of activated leukocyte cell adhesion molecule: implication for increased monocyte adhesion and migration in the CNS. J Neurosci 2011, 31:5942-5955.

22. Gorantla S, Santos K, Meyer V, Dewhurst S, Bowers WJ, Federoff HJ Gendelman HE, Poluektova L: Human dendritic cells transduced with herpes simplex virus amplicons encoding human immunodeficiency virus type 1 (HIV-1) gp120 elicit adaptive immune responses from human cells engrafted into NOD/SCID mice and confer partial protection against HIV-1 challenge. J Virol 2005, 79:2124-2132.

23. Bezzi P, Domercq M, Brambilla L, Galli R, Schols D, De Clercq E, Vescovi A, Bagetta G, Kollias G, Meldolesi J, Volterra A: CXCR4-activated astrocyte glutamate release via TNFalpha: amplification by microglia triggers neurotoxicity. Nat Neurosci 2001, 4:702-710

24. Kaul M, Garden GA, Lipton SA: Pathways to neuronal injury and apoptosis in HIV-associated dementia. Nature 2001, 410:988-994.

25. Bethel-Brown C, Yao H, Callen S, Lee YH, Dash PK, Kumar A, Buch S: HIV-1 Tat-mediated induction of platelet-derived growth factor in astrocytes: role of early growth response gene 1. J Immunol 2011, 186:4119-4129.

26. Kaul M, Ma Q, Medders KE, Desai MK, Lipton SA: HIV-1 coreceptors CCR5 and CXCR4 both mediate neuronal cell death but CCR5 paradoxically can also contribute to protection. Cell Death Differ 2007, 14:296-305.
27. Gendelman HE, Orenstein JM, Martin MA, Ferrua C, Mitra R, Phipps T, Wahl LA, Lane HC, Fauci AS, Burke DS: Efficient isolation and propagation of human immunodeficiency virus on recombinant colony-stimulating factor 1-treated monocytes. J Exp Med 1988, 167:1428-1441.

28. Dhillon NK, Peng F, Ransohoff RM, Buch S: PDGF synergistically enhances IFN-gamma-induced expression of CXCL10 in blood-derived macrophages: implications for HIV dementia. J Immunol 2007 179:2722-2730.

29. Perez-Albuerne ED, Schatteman G, Sanders LK, Nathans D: Transcriptional regulatory elements downstream of the JunB gene. Proc Natl Acad Sci U S A 1993, 90:11960-11964.

30. Peng F, Yao H, Bai X, Zhu X, Reiner BC, Beazely M, Funa K, Xiong H, Buch S: Platelet-derived growth factor-mediated induction of the synaptic plasticity gene Arc/Arg3.1. J Biol Chem 2010, 285:21615-21624.

31. Masai N, Tatebe J, Yoshino G, Morita T: Indoxyl sulfate stimulates monocyte chemoattractant protein-1 expression in human umbilical vein endothelial cells by inducing oxidative stress through activation of the NADPH oxidase-nuclear factor-kappaB pathway. Circ J 2010 74:2216-2224.

32. Ueda A, Okuda K, Ohno S, Shirai A, Igarashi T, Matsunaga K, Fukushima J, Kawamoto S, Ishigatsubo Y, Okubo T: NF-kappa B and Sp1 regulate transcription of the human monocyte chemoattractant protein-1 gene. J Immunol 1994, 153:2052-2063.

33. Panicker SR, Sreenivas P, Babu MS, Karunagaran D, Kartha CC: Quercetin attenuates Monocyte Chemoattractant Protein-1 gene expression in glucose primed aortic endothelial cells through NF-kappaB and AP-1. Pharmacol Res 2010, 62:328-336.

34. Frade JM, Mellado M, del Real G, Gutierrez-Ramos JC, Lind P, Martinez AC: Characterization of the CCR2 chemokine receptor: functional CCR2 receptor expression in B cells. J Immunol 1997, 159:5576-5584.

35. Fantuzzi L, Borghi P, Ciolli V, Pavlakis G, Belardelli F, Gessani S: Loss of CCR2 expression and functional response to monocyte chemotactic protein (MCP-1) during the differentiation of human monocytes: role of secreted MCP-1 in the regulation of the chemotactic response. Blood 1999, 94:875-883.

36. Freter RR, Alberta JA, Hwang GY, Wrentmore AL, Stiles CD: Platelet-derived growth factor induction of the immediate-early gene MCP-1 is mediated by NF-kappaB and a 90-kDa phosphoprotein coactivator. J Biol Chem 1996, 271:17417-17424.

37. Poon M, Hsu WC, Bogdanov VY, Taubman MB: Secretion of monocyte chemotactic activity by cultured rat aortic smooth muscle cells in response to PDGF is due predominantly to the induction of JE/MCP-1. Am J Pathol 1996, 149:307-317

38. Han N, Zhang DY, Wang TB, Zhang PX, Jiang BG: Calcitonin gene-related peptide induces proliferation and monocyte chemoattractant protein-1 expression via extracellular signal-regulated kinase activation in rat osteoblasts. Chin Med J (Engl) 2010, 123:1748-1753.

39. Ding GX, Zhang AH, Huang SM, Pan XQ, Chen RH: SP600125, an inhibitor of c-Jun $\mathrm{NH}$-terminal kinase, blocks expression of angiotensin II-induced monocyte chemoattractant protein-1 in human mesangial cells. World J Pediatr 2010, 6:169-176

40. Shimada H, Rajagopalan LE: Rho-kinase mediates lysophosphatidic acid-induced IL- 8 and MCP-1 production via p38 and JNK pathways in human endothelial cells. FEBS Lett 2010, 584:2827-2832

41. Remppis A, Bea F, Greten HJ, Buttler A, Wang H, Zhou Q, Preusch MR, Enk R, Ehehalt R, Katus H, Blessing E: Rhizoma Coptidis inhibits LPS-induced MCP-1/CCL2 production in murine macrophages via an AP-1 and NFkappaB-dependent pathway. Mediators Inflamm 2010, 2010:194896.

42. Eugenin EA, Osiecki K, Lopez L, Goldstein H, Calderon TM, Berman JW: CCL2/monocyte chemoattractant protein-1 mediates enhanced transmigration of human immunodeficiency virus (HIV)-infected leukocytes across the blood-brain barrier: a potential mechanism of HIV-CNS invasion and NeuroAIDS. J Neurosci 2006, 26:1098-1106.

43. Dhillon NK, Williams R, Callen S, Zien C, Narayan O, Buch S: Roles of MCP-1 in development of HIV-dementia. Front Biosci 2008, 13:3913-3918.

\section{doi:10.1186/1742-2094-9-262}

Cite this article as: Bethel-Brown et al:: Platelet-derived growth factor (PDGF)-BB-mediated induction of monocyte chemoattractant protein 1 in human astrocytes: implications for HIV-associated neuroinflammation Journal of Neuroinflammation 2012 9:262. 